\title{
Correlation between the presence of circulating tumor cells and the pathologic type and staging of non-small cell lung cancer during the early postoperative period
}

\author{
ZHANQIANG XIE $^{1 *}, \mathrm{XIAOTIAN} \mathrm{GAO}^{1^{*}}, \mathrm{KELUO} \mathrm{CHENG}^{1}$ and LISHUANG YU ${ }^{2}$ \\ Departments of ${ }^{1}$ Cardiothoracic Surgery and ${ }^{2}$ Gastroenterology, The Affiliated Hospital of \\ Guangdong Medical University, Zhanjiang, Guangdong 524001, P.R. China
}

Received May 11, 2017; Accepted July 13, 2017

DOI: $10.3892 / \mathrm{ol} .2017 .6910$

\begin{abstract}
This study investigated possible correlations between the presence of circulating tumor cells (CTCs) and the pathologic types and staging of non-small cell lung cancer (NSCLC) during the early postoperative period. Sixty-nine patients with NSCLC were enrolled in the study. Clinical staging was performed by postoperative pathological examination and imaging. Multiple mRNA in situ analyses targeting specifically expressed genes were carried out to identify the presence of CTCs. Correlations between age, sex, TNM stage and pathological types with the detection rate of CTCs were also established. The results showed the positivity rate of CTCs in patients $>55$ years was significantly higher than that of patients $<55$ years (94.74 vs. $70.97 \%$, $\mathrm{P}<0.05)$. There was no significant difference in the positivity rate of CTCs between male and female patients (85.71 vs. $85.29 \%, \mathrm{P}>0.05)$. The correlations between the detection rate of epithelial type or mixed type CTCs with tumor size, lymph node metastasis and distant metastasis TNM in patients with NSCLC were not significant $(\mathrm{P}>0.05)$. However, higher TNM stages correlated with higher detection rates of mesenchymal CTCs $(\mathrm{P}<0.05)$. There were also significant differences in the detection rates of CTCs amongst the three different pathologic types (adenocarcinoma, squamous cell and large cell carcinomas $)(\mathrm{P}<0.05)$. Based on our results, the detection of mesenchymal CTCs during the early postoperative period can help prognosticate the recurrence and metastasis of NSCLC, which is beneficial to the development of individualized treatment strategies.
\end{abstract}

Correspondence to: Dr Keluo Cheng, Department of Cardiothoracic Surgery, The Affiliated Hospital of Guangdong Medical University, 57 Renmin Avenue South, Xiashan, Zhanjiang, Guangdong 524001, P.R. China

E-mail: keluo_cheng@hotmail.com

${ }^{*}$ Contributed equally

Key words: non-small cell lung cancer, circulating tumor cells, pathological type, pathological stage

\section{Introduction}

Lung cancer, or bronchogenic carcinoma, is a malignant tumor originating in the bronchial mucosa. It includes non-small cell lung cancer (NSCLC) and small cell lung cancer. NSCLC, which can be further divided into adeno-squamous cell, adenosquamous and large cell carcinomas, accounts for $85 \%$ of all the cases of lung cancer (1). In recent years, the incidence of lung cancer has been increasing all over the world and lung cancer is one of the main causes of death by malignant tumors. In some developed areas of countries including some in China, the incidence of lung cancer has ranked first among all malignant tumors (2) and at least 100 million deaths are caused by lung cancer every year (3). The treatment of lung cancer is still based on a combination of surgical resection and chemotherapy. The five-year survival rate of the patients is no more than one third; with the survival time of advanced lung cancer patients being even shorter and a median survival time spanning only 8 to 12 months (4). Distant metastasis and a postoperative high recurrence rate are the main factors leading to the death of patients with lung cancer (5). Surgical resection of the lesion is the main treatment method for patients with stage I NSCLC, however one-third of patients will have a relapse within five-years after surgery. Systemic metastasis causes most postoperative recurrences and distant metastasis can also occur in patients with early clinical stage disease (6). The process of malignant tumor metastasis is very complex. It has been confirmed that the invasion of peripheral blood circulation by tumor cells is one of the main ways of distant metastasis dissemination (7). Circulating tumor cells (CTCs) are tumor cells found in the peripheral blood circulation, their shedding from the primary solid malignancy can be spontaneous or caused by medical treatment $(8,9)$. It has been reported that the presence of CTCs is closely related to the prognosis of NSCLC (10-12). In this study, we investigated the correlation between the detection rate of CTCs during the early postoperative period with age, sex, where T represented tumor size; N, lymph node metastasis degree; and M, the presence of distant metastasis TNM stage and pathological type of patients with NSCLC, so as to provide a theoretical basis for the development of individualized treatment strategies for the patients. 


\section{Materials and methods}

General information. Patients diagnosed with NSCLC were selected during their hospitalization in the Affiliated Hospital of Guangdong Medical University, from a period starting in April 2016 until April 2017. There were 35 males and 34 females and their ages ranged from 28 to 80 years with an average of $58.13 \pm 20.15$ years.

Inclusion criteria included patients with NSCLC confirmed by histopathological examination who had not received any radioactive or antitumor drug treatments and who signed informed consent forms.

Patients without histopathological diagnosis of NSCLC or those with a history of other types of malignant tumors were excluded from the study, as well as patients who received radiotherapy and/or chemotherapy before surgery; those with more than one surgical treatment, patients with postoperative recurrences or those who refused to cooperate with the treatment.

In cases were patients decided to withdraw from the study or if they had to be transferred to another hospital a 1:1 ratio (response measure:supplement) was maintained enrolling new patients by following the inclusion and exclusion criteria.

Medical ethics: All patients or their family members signed informed consent forms; the treatment safety of the patients was ensured by adhering to relevant principles of clinical guidelines; all diagnosis and treatment records were kept confidential to protect the privacy of patients.

In order to conduct a double-blind trial the researchers were divided into four groups. Group 1 was responsible for the patient's screening and grouping; 2, performed the treatment; 3 , undertook observation and data collection; and 4 , the statistical analysis and manuscript writing. Also, the experimental grouping was kept strictly confidential and the operations of each of the four researcher groups were unknown to the others.

Methods and testing principles. For sample collections, $10 \mathrm{ml}$ of blood were extracted from the median cubital vein of each patient and transferred to an EDTA anticoagulant tube. The samples were fully mixed and kept in storage at room temperature for $30 \mathrm{~min}$.

In order to perform human peripheral blood CTC enrichment, nanotechnology was used for red blood cell lysis. After centrifugation, the supernatant was discarded and the pellet was filtered, followed by fixation in formaldehyde solution for $1 \mathrm{~h}$.

Multiple mRNA in situ analysis to identify the enriched CTCs. After incubation with permeabilizer for $5 \mathrm{~min}$ and with digestive enzyme for $1 \mathrm{~h}$, the probe solution was added, followed by incubation at $40^{\circ} \mathrm{C}$ for $3 \mathrm{~h}$. Next, pre-amplification, amplification and colorization solutions (Beyotime Biotechnology, Nanjing, China) were added in that order, followed by incubation at $40^{\circ} \mathrm{C}$ for $0.5 \mathrm{~h}$. The anti-fluorescent quenching reagent (Biosharp, Hefei, China) was then added and results were observed $5 \mathrm{~min}$ later.

Criteria for TNM staging and histological typing. The results of postoperative pathological examination and imaging of 69 NSCLC patients were analyzed for clinical TNM staging.
Table I. Comparison of CTC detection rate between the age groups of NSCLC patients.

\begin{tabular}{lrrrrc}
\hline & \multicolumn{2}{c}{ Age } & & \\
\cline { 2 - 3 } N Stage & $>55$ & $>55$ & & $\chi^{2}$ value & P-value \\
\hline CTC Positive & 36 & 22 & - & - \\
CTC Negative & 2 & 9 & - & - \\
Total & 38 & 31 & - & - \\
Positivity rate & $94.74 \%$ & $70.97 \%$ & 7.995 & $<0.05$ \\
\hline
\end{tabular}

CTC, circulating tumor cells; NSCLC, non-small cell lung cancer.

Table II. Comparison of CTC detection rate between males and females of NSCLC patients.

\begin{tabular}{lrcrc}
\hline & \multicolumn{2}{c}{ Age } & & \\
\cline { 2 - 3 } N Stage & Male & Female & $\chi^{2}$ value & P-value \\
\hline CTC Positive & 30 & 29 & - & - \\
CTC Negative & 5 & 5 & - & - \\
Total & 35 & 34 & - & - \\
Positivity rate & $85.71 \%$ & $85.29 \%$ & 2.004 & $>0.05$ \\
\hline
\end{tabular}

CTC, circulating tumor cells; NSCLC, non-small cell lung cancer.

The histological type was determined by a pathologist. Results showed that, among the 69 patients with NSCLC, there were 16 cases of squamous cell carcinoma; 48 , of adenocarcinoma; and 5 , of large cell carcinoma.

Statistical analysis. The data in this study were all analyzed by SPSS20.0 statistical analysis software (IBM, Armonk, NY, USA). Countable data are expressed as percentages (\%). $\chi^{2}$ test was performed and a $\mathrm{P}<0.05$ was considered to indicate a statistically significant difference.

\section{Results}

Correlation of age and sex of patients with detection rate of CTCs. Data of CTCs detection numbers in different age and sex groups showed that 36 of the 38 patients aged over 55 were positive, and only 2 were negative; also 22 of the 31 patients aged below 55 were positive and 9 were negative. The positive rate of CTCs was significantly higher in patients over 55 years than in those younger than 55 ( 94.74 vs. $70.97 \%, \mathrm{P}<0.05)$. Then, from the 36 male patients, 30 were CTC positive and 6 were negative, and of 34 female patients, 29 were CTC positive and 5 were negative. No significant difference was found in CTC positivity between male and females (85.71 vs. $85.29 \%$, $\mathrm{P}>0.05$ ) (Tables I and II).

Correlation between the detection rate of different types of CTCs with tumor size. No significant differences in the detection rate of epithelial and mixed type CTCs were found 
Table III. Correlation between detection rate of different types of CTCs with T staging in NSCLC patients.

\begin{tabular}{|c|c|c|c|c|}
\hline \multirow[b]{2}{*}{ T Stage } & \multirow[b]{2}{*}{ Cases } & \multicolumn{3}{|c|}{ Different types of CTCs } \\
\hline & & Epithelial type & Mesenchymal type & Mixed type \\
\hline $\mathrm{T} 1$ & 16 & $25.00 \%(4 / 16)$ & $12.50 \%(2 / 16)$ & $68.75 \%(11 / 16)$ \\
\hline $\mathrm{T} 2$ & 28 & $46.43 \%(13 / 28)$ & $39.29 \%(11 / 28)$ & $89.29 \%(25 / 28)$ \\
\hline $\mathrm{T} 3$ & 13 & $38.46 \%(5 / 13)$ & $46.15 \%(6 / 13)$ & $100.00 \%(13 / 13)$ \\
\hline $\mathrm{T} 4$ & 12 & $33.33 \%(4 / 12)$ & $58.33 \%(7 / 12)$ & $100.00 \%(12 / 12)$ \\
\hline$\chi^{2}$ value & - & 2.53 & 8.22 & 6.81 \\
\hline P-value & - & $>0.05$ & $<0.05$ & $>0.05$ \\
\hline
\end{tabular}

CTC, circulating tumor cells; NSCLC, non-small cell lung cancer.

Table IV. Correlation between detection rate of different types of CTCs with N stages in NSCLC patients.

\begin{tabular}{|c|c|c|c|c|}
\hline \multirow[b]{2}{*}{ T Stage } & \multirow[b]{2}{*}{ Cases } & \multicolumn{3}{|c|}{ Different types of CTCs } \\
\hline & & Epithelial type & Mesenchymal type & Mixed type \\
\hline $\mathrm{T} 1$ & 35 & $31.43 \%(11 / 35)$ & $28.57 \%(10 / 35)$ & $88.57 \%(31 / 35)$ \\
\hline $\mathrm{T} 2$ & 14 & $42.86 \%(6 / 14)$ & $35.71 \%(5 / 14)$ & $78.57 \%(11 / 14)$ \\
\hline $\mathrm{T} 3$ & 12 & $33.33 \%(4 / 12)$ & $50.00 \%(6 / 12)$ & $75.00 \%(9 / 12)$ \\
\hline $\mathrm{T} 4$ & 8 & $37.50 \%(3 / 8)$ & $62.50 \%(5 / 8)$ & $75.00 \%(6 / 8)$ \\
\hline$\chi^{2}$ value & - & 1.87 & 3.44 & 0.60 \\
\hline P-value & - & $>0.05$ & $<0.05$ & $>0.05$ \\
\hline
\end{tabular}

CTC, circulating tumor cells; NSCLC, non-small cell lung cancer.

Table V. Correlation between the detection rate of different types of CTCs with M stages in NSCLC patients.

\begin{tabular}{|c|c|c|c|c|}
\hline \multirow[b]{2}{*}{ T Stage } & \multirow[b]{2}{*}{ Cases } & \multicolumn{3}{|c|}{ Different types of CTCs } \\
\hline & & Epithelial type & Mesenchymal type & Mixed type \\
\hline M0 & 53 & $35.85 \%(19 / 53)$ & $32.08 \%(17 / 53)$ & $88.68 \%(47 / 53)$ \\
\hline M1 & 16 & $37.50 \%(6 / 16)$ & $62.50 \%(10 / 16)$ & $81.25 \%(13 / 16)$ \\
\hline$\chi^{2}$ value & & 0.13 & 3.99 & 0.59 \\
\hline $\mathrm{P}$-value & & $>0.05$ & $<0.05$ & $>0.05$ \\
\hline
\end{tabular}

CTC, circulating tumor cells; NSCLC, non-small cell lung cancer.

amongst patients with different $\mathrm{T}$ stages (T1, T2, T3 and T4) $(\mathrm{P}>0.05)$. However, the detection rate of mesenchymal CTCs increased with higher $\mathrm{T}$ stages $(\mathrm{P}<0.05)$ (Table III).

Correlation between the detection rate of different types of CTCs with lymph node metastasis. No significant differences in the detection rate of epithelial and mixed type CTCs were found among patients with different $\mathrm{N}$ stages $(\mathrm{P}>0.05)$, but the positive rate of mesenchymal CTCs increased with higher $\mathrm{N}$ stages $(\mathrm{P}<0.05)$ (Table IV).

Correlation between the detection rate of different types of CTCs with the presence of distant metastasis. No significant differences in the detection rate of epithelial and mixed type CTCs were found among patients with different $M$ stages $(\mathrm{P}>0.05)$. Nevertheless, the positive rate of mesenchymal CTCs was significantly lower in patients with M0 stage than in patients with M1 stage (32.08 vs. $60.00 \%, \mathrm{P}<0.05)$ (Table V).

Correlation between the detection rate of different types of CTCs with pathological stages. No significant differences in the detection rate of epithelial and mixed type CTCs were found among patients with different pathological stages (I, II, III and IV), P>0.05, but the positive rate of mesenchymal CTCs increased with each higher pathological stage $(\mathrm{P}<0.05)$ (Table VI). 
Table VI. Correlation between the detection rate of different types of CTCs with pathological stages (I, II, III and IV) in NSCLC patients.

\begin{tabular}{lcccc}
\hline & & \multicolumn{3}{c}{ Different types of CTCs } \\
\cline { 3 - 4 } T Stage & Cases & Epithelial type & Mesenchymal type & Mixed type \\
\hline I & 23 & $34.78 \%(8 / 23)$ & $21.74 \%(5 / 23)$ & $82.61 \%(19 / 23)$ \\
II & 18 & $44.44 \%(8 / 18)$ & $27.78 \%(5 / 18)$ & $83.33 \%(15 / 18)$ \\
III & 15 & $33.33 \%(5 / 15)$ & $60.00 \%(9 / 15)$ & $100.00 \%(15 / 15)$ \\
IV & 13 & $30.77 \%(4 / 13)$ & $69.23 \%(9 / 13)$ & $84.61 \%(11 / 13)$ \\
$\chi^{2}$ value & - & 1.31 & 8.34 & 1.19 \\
P-value & - & $>0.05$ & $<0.05$ & $>0.05$ \\
\hline
\end{tabular}

CTC, circulating tumor cells; NSCLC, non-small cell lung cancer.

Table VII. Correlation between the positive rate of CTCs after surgery with different pathological types in NSCLC patients.

\begin{tabular}{lcccc}
\hline Pathological types & $\begin{array}{c}\text { CTCs } \\
\text { positive }\end{array}$ & $\begin{array}{c}\text { CTCs } \\
\text { negative }\end{array}$ & Total & $\begin{array}{c}\text { Positive } \\
\text { rate }\end{array}$ \\
\hline $\begin{array}{l}\text { Adenocarcinoma } \\
\text { Squamous cell }\end{array}$ & 40 & 8 & 48 & $83.33 \%$ \\
$\begin{array}{l}\text { carcinoma } \\
\begin{array}{l}\text { Large cell } \\
\text { carcinoma }\end{array}\end{array}$ & 14 & 2 & 16 & $87.50 \%$ \\
$\begin{array}{l}\text { Total } \\
\chi^{2} \text { value }\end{array}$ & 55 & 14 & 69 & $79.71 \%$ \\
P-value & - & - & - & 8.362 \\
\hline
\end{tabular}

CTC, circulating tumor cells; NSCLC, non-small cell lung cancer.

Correlation between the positive rate of CTCs with different pathological types. Among the 48 cases of adenocarcinoma, 40 were CTC positive and 8 were negative. Among the 16 cases of squamous cell carcinoma, 14 were CTC positive and 2 were negative. Among 5 cases of large cell carcinoma, 1 was CTC positive and 4 were negative. There were significant differences in the positivity rates of CTCs among patients with three different pathological types of NSCLC $(\mathrm{P}<0.05)$ (Table VII).

\section{Discussion}

Among all malignant tumors, the morbidity and mortality rates of lung cancer remain some of the highest. Furthermore, in recent years, the incidence of lung cancer has shown an increasing trend. While the incidence rate for males in China is still lower than that in some developed countries, the incidence for females has reached the levels of developed countries $(12,13)$. CTC invasion is one of the major factors leading to distant metastases of malignant tumors $(14,15)$. Reports have confirmed that epithelial-mesenchymal transitions (EMTs) can occur in CTCs (16). Gene expression profiles (epithelial mesenchymal markers, transcription factors) of
CTCs change during EMTs and so does the morphology and mobility of the cells (17). CTCs that undergo EMT may have characteristics known to stem cells. Tumor cell invasion and migration abilities can be induced by changes in adhesion affinity, which in turn lead to increased survival rates of CTCs in peripheral blood and easier access into other organs and tissues, resulting in the establishment of metastatic lesions (18). Therefore, EMTs are important in recurrences and metastases by CTCs $(19,20)$. CTCs with stem cell characteristics have been found in malignant tumors of breast, liver and lung cancers and it has been confirmed that recurrences and metastases of malignant tumors are mostly caused by tumor stem cells (21). A relationship between drug resistance to cancer treatments and the presence of CTCs has also been described (22).

In this study we found no correlations between the detection rate of epithelial and mixed type CTCs with tumor size, presence of lymph node metastasis or distant metastasis (TNM stages), P $>0.05$. However, the detection rate of mesenchymal CTCs, correlated with higher TNM stages indicating that mesenchymal CTCs are closely related to the clinicopathological stages of NSCLC. According to a study, it has been reported that the genotypic characteristics and phenotypic expression profiles of primary tumor cells are very different from those of metastatic tumor cells (23). It is worth noting that the positive rate of mesenchymal CTCs in patients without distant metastases was $32.08 \%$ and it was inferred that, as opposed to conventional imaging methods, monitoring CTCs may be useful for the early diagnosis of micrometastasis. Monitoring the CTCs in peripheral blood can be helpful for the detection of recurrence and metastasis, which should contribute to the improvement of follow-up treatment programs, thereby increasing the survival rates. The detection of changes in CTCs before and after surgery or chemotherapy could be used for the early diagnosis of metastasis and recurrence of lung cancer and his would have a far-reaching impact on the evaluation of the sensitivity of the treatment program, clinical staging of early lung cancer, efficacy of individualized treatment and prognosis.

Different types of CTCs cause various degrees of malignancy. Regardless of the number of CTCs, their molecular characteristics and different types may have more critical 
effects on tumor metastases (24). Therefore, detection of the CTC molecular characteristics should be useful in predicting metastasis and recurrence of cancers, which in turn would improve the treatment plan. After surgical removal of a primary tumor, a certain number of CTCs survive in peripheral blood. Most of the CTCs in peripheral blood can be eliminated by drug treatment and the immune response, but a small amount of CTCs, especially mesenchymal CTCs, may not be cleared due to their drug resistance or immune system escape (25) and small lesions may form in other organs and tissues (26). It has been speculated that the existence of mesenchymal CTCs in peripheral blood can promote metastasis and recurrence of cancer and increases the degree of malignancy (27).

Among the 5 patients with large cell carcinoma in this study, only one of them showed CTC positivity. This finding is contrary to the hypothesis that the poorly differentiated and highly malignant larger cell carcinoma results from high levels of CTCs. This may be explained by the unique genotypic changes that are characteristic of large cell carcinomas, which are different from those of adenocarcinoma, squamous cell carcinoma and other types of lung cancers. For example, some of the CTCs found in large cell carcinomas express the characteristic genes of 'multifunctional precursor cells' (28). So those CTCs cannot be effectively detected by the method used in this study.

In summary, our results support the use of CTC detection as a method to diagnose latent micrometastases in early lung cancers in order to aid in prognosis and treatment planning $(29,30)$. So this method should be popularized in clinical practice. However, further studies with large numbers of patients are needed to validate the accuracy of the CTC detection method and improve its accuracy.

\section{References}

1. Ferlay J, Soerjomataram I, Dikshit R, Eser S, Mathers C, Rebelo M, Parkin DM, Forman D and Bray F: Cancer incidence and mortality worldwide: Sources, methods and major patterns in GLOBOCAN 2012. Int J Cancer 136: E359-E386, 2015.

2. Woodard GA, Jones KD and Jablons DM: Lung cancer staging and prognosis. Cancer Treat Res 170: 47-75, 2016.

3. Jeon JH, Kang CH, Kim HS, Seong YW, Park IK, Kim YT and Kim JH: Video-assisted thoracoscopic lobectomy in non-small-cell lung cancer patients with chronic obstructive pulmonary disease is associated with lower pulmonary complications than open lobectomy: A propensity score-matched analysis. Eur J Cardiothorac Surg 45: 640-645, 2014.

4. Huang D, Fang F and Xu F: Hyperoxia induces inflammation and regulates cytokine production in alveolar epithelium through TLR2/4-NF- $\kappa$ B-dependent mechanism. Eur Rev Med Pharmacol Sci 20: 1399-1410, 2016.

5. Zuo X, Zhang J, Zhang Y, Hsu SC, Zhou D and Guo W: Exo70 interacts with the Arp2/3 complex and regulates cell migration. Nat Cell Biol 8: 1383-1388, 2006.

6. Saygideğer-Kont Y, Minas TZ, Jones H, Hour S, Çelik H, Temel I, Han J, Atabey N, Erkizan HV, Toretsky JA, et al: Ezrin enhances EGFR signaling and modulates erlotinib sensitivity in non-small cell lung cancer cells. Neoplasia 18: 111-120, 2016.

7. Hong Y, Li Z and Zhang Q: A circulating tumor cell cluster-based model for tumor metastasis (Hypothesis). Oncol Lett 12: 4891-4895, 2016

8. Ilie M, Hofman V, Long E, Bordone O, Selva E, Washetine K, Marquette $\mathrm{CH}$ and Hofman P: Current challenges for detection of circulating tumor cells and cell-free circulating nucleic acids and their characterization in non-small cell lung carcinoma patients. What is the best blood substrate for personalized medicine? Ann Transl Med 2: 107, 2014.
9. Reeh M, Effenberger KE, Koenig AM, Riethdorf S, Eichstädt D, Vettorazzi E, Uzunoglu FG, Vashist YK, Izbicki JR, Pantel K, et al: Circulating tumor cells as a biomarker for preoperative prognostic staging in patients with EC. Ann Surg 261: 1124-1130, 2015 .

10. Fusi A, Metcalf R, Krebs M, Dive C and Blackhall F: Clinical utility of circulating tumour cell detection in non-small-cell lung cancer. Curr Treat Options Oncol 14: 610-622, 2013.

11. Li H, Song P, Zou B, Liu M, Cui K, Zhou P, Li S and Zhang B: Circulating tumor cell analyses in patients with esophageal squamous cell carcinoma using epithelial Marker-Dependent and-Independent approaches. Medicine (Baltimore) 94: e1565, 2015.

12. Zhang Z, Xiao Y, Zhao J, Chen M, Xu Y, Zhong W, Xing J and Wang M: Relationship between circulating tumour cell count and prognosis following chemotherapy in patients with advanced non-small-cell lung cancer. Respirology 21: 519-525, 2016.

13. Lagerwaard FJ, Aaronson NK, Gundy CM, Haasbeek CJ, Slotman BJ and Senan S: Patient-reported quality of life after stereotactic ablative radiotherapy for early-stage lung cancer. J Thorac Oncol 7: 1148-1154, 2012.

14. Donato BM, Burns L, Willey V, Cohenuram M, Oliveria S and Yood MU: Treatment patterns in patients with advanced breast cancer who were exposed to an anthracycline, a taxane and capecitabine: A descriptive report. Clin Ther 32: 546-554, 2010.

15. Khan MS, Kirkwood A, Tsigani T, Garcia-Hernandez J, Hartley JA, Caplin ME and Meyer T: Circulating tumor cells as prognostic markers in neuroendocrine tumors. J Clin Oncol 31: 365-372, 2013.

16. Stovold R, Blackhall F, Meredith S, Hou J, Dive C and White A: Biomarkers for small cell lung cancer: Neuroendocrine, epithelial and circulating tumour cells. Lung Cancer 76: 263-268, 2012.

17. Reijm EA, Sieuwerts AM, Smid M, Vries JB, Mostert B, Onstenk W, Peeters D, Dirix LY, Seynaeve CM, Jager A, et al: An 8-gene mRNA expression profile in circulating tumor cells predicts response to aromatase inhibitors in metastatic breast cancer patients. BMC Cancer 16: 123, 2016.

18. Yu M, Bardia A, Wittner BS, Stott SL, Smas ME, Ting DT, Isakoff SJ, Ciciliano JC, Wells MN, Shah AM, et al: Circulating breast tumor cells exhibit dynamic changes in epithelial and mesenchymal composition. Science 339: 580-584, 2013.

19. Lecharpentier A, Vielh P, Perez-Moreno P, Planchard D, Soria JC and Farace F: Detection of circulating tumour cells with a hybrid (epithelial/mesenchymal) phenotype in patients with metastatic non-small cell lung cancer. Br J Cancer 105: 1338-1341, 2011.

20. Hosokawa M, Yoshikawa T, Negishi R, Yoshino $T$, Koh Y, Kenmotsu H, Naito T, Takahashi T, Yamamoto N, Kikuhara Y, et al: Microcavity array system for size-based enrichment of circulating tumor cells from the blood of patients with small-cell lung cancer. Anal Chem 85: 5692-5698, 2013.

21. Catenacci DV, Chapman CG, Xu P, Koons A, Konda VJ, Siddiqui UD and Waxman I: Acquisition of portal venous circulating tumor cells from patients with pancreaticobiliary cancers by endoscopic ultrasound. Gastroenterology 149: 1794-1803.e4, 2015.

22. Zhang Z, Shiratsuchi H, Palanisamy N, Nagrath S and Ramnath N: Expanded circulating tumor cells from a patient with ALK-positive lung cancer present with EML4-ALK rearrangement along with resistance mutation and enable drug sensitivity testing: A Case Study. J Thorac Oncol 12: 397-402, 2017.

23. Hyun KA, Kwon K, Han H, Kim SI and Jung HI: Microfluidic flow fractionation device for label-free isolation of circulating tumor cells (CTCs) from breast cancer patients. Biosens Bioelectron 40: 206-212, 2013.

24. Bystricky B, Jurisova S, Karaba M, Minarik G, Benca J, Sedlácková T, Tothova L, Vlkova B, Cierna Z, Janega P, et al: Relationship between circulating tumor cells and tissue plasminogen activator in patients with early breast cancer. Anticancer Res 37: 1787-1791, 2017.

25. Aieta M, Facchinetti A, De Faveri S, Manicone M, Tartarone A, Possidente L, Lerose R, Mambella G, Calderone G, Zamarchi R, et al: Monitoring and characterization of circulating tumor cells (CTCs) in a patient with EML4-ALK-positive non-small cell lung cancer (NSCLC). Clin Lung Cancer 17: e173-e177, 2016.

26. Tsai WS, Chen JS, Shao HJ, Wu JC, Lai JM, Lu SH, Hung TF, Chiu YC, You JF, Hsieh PS, et al: Circulating tumor cell count correlates with colorectal neoplasm progression and is a prognostic marker for distant metastasis in non-metastatic patients. Sci Rep 6: 24517, 2016. 
27. Chen X, Wang X, He H, Liu Z, Hu JF and Li W: Combination of circulating tumor cells with serum carcinoembryonic antigen enhances clinical prediction of non-small cell lung cancer. PLoS One 10: e0126276, 2015.

28. Swanson SJ, Miller DL, McKenna RJ Jr, Howington J, Marshall MB, Yoo AC, Moore M, Gunnarsson CL and Meyers BF: Comparing robot-assisted thoracic surgical lobectomy with conventional video-assisted thoracic surgical lobectomy and wedge resection: Results from a multihospital database (Premier). J Thorac Cardiovasc Surg 147: 929-937, 2014.
29. Ross K, Pailler E, Faugeroux V, Taylor M, Oulhen M, Auger N, Planchard D, Soria JC, Lindsay CR, Besse B, et al: The potential diagnostic power of circulating tumor cell analysis for non-small-cell lung cancer. Expert Rev Mol Diagn 15: 1605-1629, 2015.

30. Mego M, Giordano A, De Giorgi U, Masuda H, Hsu L, Giuliano M, Fouad TM, Dawood S, Ueno NT, Valero V, et al: Circulating tumor cells in newly diagnosed inflammatory breast cancer. Breast Cancer Res 17: 2, 2015. 